\title{
INFLUENCE OF DIAZINON ON IRON AVILABILITY IN INDIAN SPINACH WITH DIFFERENT DOSES OF RICE HULL AS A BIOREMEDIANT
}

\author{
Alam, M. D., T. F. Khan and F. Akhter \\ Department of Soil, Water and Environment, University of Dhaka, Dhaka 1000, Bangladesh
}

\begin{abstract}
A pot culture experiment was conducted to study the effects of diazinon pesticide on the availability of heavy metals of plant with the application of different doses of rice hull. For this purpose, an upland leafy vegetable, namely Indian spinach (Basella alba) was used. Seven different treatments including a control following a randomized complete block design (RCBD) were used in the experimental set-up. Three soil and plant sample were taken at three different periods, viz. 6 hours, 15 days and 30 days, after application of the diazinon. The soil and plant samples were analyzed in the laboratory to determine their contents of $\mathrm{Fe}$ and diazinon pesticide. The soil contained lower concentration of Fe compared to that of the plant. In most of the cases, soil Fe decreased gradually in the sampling periods. Soil diazinon content increased and then decreased at third sampling period for all treatments. The rice hull as bioremediant was able to restrict the uptake of diazinon by plants and could bring the pesticide into the soil system. The application of diazinon initially affected soil, but it disappeared gradually from the soil with time due to degradation, evaporation and transportation. At second sampling period, the diazinon content was highest in both soil and plant. The present study showed positive response of rice hull as bioremediation and this finding can be used to minimize the harmful effects of pesticide.
\end{abstract}

Key words: Pot culture, diazinon, heavy metal, rice hull, Indian spinach, treatment, bioremediant.

\section{INTRODUCTION}

Indian spinach (Basella alba) originates from Asia but is now grown in most tropical regions as a leafy vegetable crop. It is usually cooked but can also be used raw in salads. Rice hulls (or rice husks) are the hard protecting coverings of seeds of grains of rice. In addition to protecting rice during the growing season, rice hulls can be put to use as building material, fertilizer, insulation material, or fuel. In medium land, rice even under puddle conditions during the critical period warrants an effective as well as economic weed control practice to prevent reduction in rice yield due to the weeds that range from 28 to $48 \%$ (Behera and Singh 1999).

Diazinon is a synthetic organophosphate pesticide first registered in the United States in 1956. It is used in agriculture as an insecticide, acaricide and nematicide (Behera and Singh 1999). Increasing evidence shows that eating fruit and vegetables regularly reduces the risk of cancers, high blood pressure, heart disease, diabetes, stroke, and other chronic diseases.

Only cereal production in Bangladesh reduced at 20 million tons in 1992 which was nearly six million tons in 1950 (Habibullah and Huq 1992). Such success was possible due to the use of pesticides for effective protection against pests and diseases along with other modern agricultural attributes. With the intensification of agriculture and increasing usage of pesticides, there is an urgent need to study the side effects of pesticides on various soil properties and on the host plant. Currently 20 insecticides, 18 fungicides, three herbicides and two rodenticides are being used in Bangladesh (Ahmed 1982).

The use of various agrochemicals in the country is very much indiscriminate and therefore the pollution of environmental resources is very high. The transport, persistence and degradation of pesticides in soil depend on their chemical properties as well as physical, chemical and biological properties of the soil. All these factors affect desorption, volatilization, degradation, uptake, run-off and leaching of pesticides (Shegunoa et al. 2007, Toan et al. 2007). 
Most of the pesticides are not easily degradable; they persist in soil for a long period, leach to ground water and ultimately contaminate the environment. Depending on their chemical properties they can enter into organism, bio-accumulate in the food chain and consequently influence human health. As a whole, intensive application of pesticide results in several negative effects in the environment that cannot be ignored (Russell and Schultz 2009). Scientists are now introducing alternative management techniques to reduce the use of pesticides. The present study was carried out to evaluate the effects of diazinon on some soil chemical properties and accumulation of diazinon in Indian spinach under different doses of rice hull.

\section{Soil sampling and processing}

\section{MATERIAL AND METHODS}

A composite soil sample was collected from a field of Moragasa village situated in Khoksha_Upazila of Kustia district. The collected soil samples were air-dried for three days. Visible roots and debris were removed from the soil manually. After air-drying larger and massive aggregates were broken down using a wooden hammer. Ground samples were sieved through a $2 \mathrm{~mm}$ stainless steel sieve and kept in polyethylene bags for further physico-chemical analysis (Carter and Gregorich 2007).

The soil belongs to the Sarail series with sandy loam texture. It had a pH of 8.2 and EC $1000 \mu \mathrm{S} / \mathrm{m}$. The soil had nitrogen, phosphorus, potassium, sulfur, calcium and magnesium (all are total) content of $1.5 \%, 1.4 \%, 0.006 \%, 0.00063 \%, 3.3 \%$ and $1.2 \%$, respectively.

\section{Experimental set-up}

Seven treatments with two replications each were arranged following a randomized complete block design (RCBD). The treatments were $\mathrm{T}_{1:} \mathrm{Di}_{0.5} \mathrm{RH}_{0.0}, \mathrm{~T}_{2}: \mathrm{Di}_{0.5} \mathrm{RH}_{2.0} / 2 \mathrm{~kg}$ soil, $\mathrm{T}_{3:} \mathrm{Di}_{0.5} \mathrm{RH}_{4.0} / 2 \mathrm{~kg}$ soil, $\mathrm{T}_{4 \text { : }}$ $\mathrm{Di}_{1.0} \mathrm{RH}_{0.0} / 2 \mathrm{~kg}$ soil, $\mathrm{T}_{5}$ : $\mathrm{Di}_{1.0} \mathrm{RH}_{2.0} / 2 \mathrm{~kg}$ soil, $\mathrm{T}_{6}$ : $\mathrm{Di}_{1.0} \mathrm{RH}_{4.0} / 2 \mathrm{~kg}$ soil and $\mathrm{T}_{7:} \mathrm{Di}_{0.0} \mathrm{RH}_{0.0} / 2 \mathrm{~kg}$ (without Diazinon and rice hull) soil. A total of fourteen bottom closed pots was used. Each pot was filled with two kilogram of soil. In the present study, three different dozes of diazinon, such as $0.0,0.5$ and $1.0 \mathrm{ml} / 2$ $\mathrm{kg}$ of soil and rice hull at the rate of $0.0,2.0$ and $4.0 \mathrm{~g} / 2 \mathrm{~kg}$ soil were applied. The study was carried out in the net house of the Department of Soil, Water and Environment, University of Dhaka. A basal dose of $\mathrm{N}$ as urea, $\mathrm{P}$ as TSP and $\mathrm{K}$ as muriate of potash was added at the rate of 70,15 and $50 \mathrm{mg} / \mathrm{kg}$, respectively (BARC 2012). Three seeds of Indian spinach (Basella alba) were sown in each pot. After 15 days of sowing, diazinon and rice hull were applied accordingly.

\section{Sample preparation and analysis}

Three sampling times were chosen for soil and plant sample collection. The first sampling was made 6 hours later after the application of diazinon and rice hull. The second sampling was made 15 days after the first sampling and finally the third sampling was made after 30 days of the first sampling. Plants were watered twice daily in the morning and evening. Intercultural operations were done whenever necessary. The soil samples were dried and processed for chemical analysis following Huq and Alam (2005). The soil samples were extracted with hydrochloric-sulfuric acid according to Huq and Alam (2005) and Jackson (1958).

The harvested plants were washed with tap water and wiped with pieces of tissue paper. The plant sample was cut into small pieces, air-dried, and oven-dried at $70^{\circ} \mathrm{C}$ for 48 hours. The plant samples were ground, sieved through a $0.2 \mathrm{~mm}$ sieve and stored in polyethylene bags for further analyses. The plant samples were digested with concentrated nitric acid in block digester (Jackson 1958). Diazinon in plant samples was determined by standard methods and extracted with hydrochloric- sulfuric acid (4:1) and volume up to $100 \mathrm{ml}$. Iron contents of both soil and plant samples were determined by the 
Spectrophotometer following the standard procedure (Carter and Gregorich 2007, Brian 2012). Also, diazinon contents were determined in both soil and plant. All graphs were plotted by using Microsoft Excel.

\section{Effect on iron content}

\section{RESULTS AND DISCUSSION}

Initially the soil had iron content of $1.2 \%$. The iron content of the soil varied significantly at three different sampling periods. In most of the cases, soil Fe decreased gradually in the sampling periods (Fig. 1). In few cases $\left(\mathrm{Di}_{0.5} \mathrm{RH}_{2.0}\right.$-treatment 2, $\mathrm{Di}_{0.5} \mathrm{RH}_{4.0}$-treatment 3 and $\mathrm{Di}_{0.0} \mathrm{RH}_{0.0}$-treatment 7 ), soil Fe contents were first decreased and then gradually increased in third sampling period. It was observed that soil $\mathrm{pH}$ was increased in the sampling periods. The decreased content of Fe might be due to increased soil $\mathrm{pH}$ as high soil $\mathrm{pH}$ reduces Fe availability (Fanrong et al. 2011).

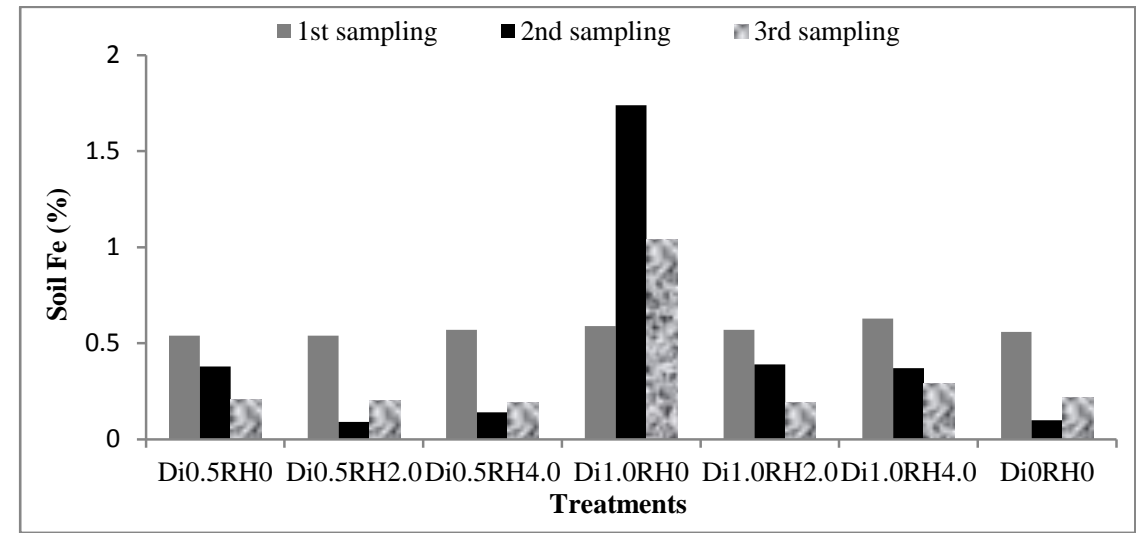

Fig. 1. Soil iron at different treatments during three sampling periods.

The exact mechanisms responsible for reducing availability differ, but can include formation of low solubility compounds, greater retention by soil colloids (clays and organic matter) as well as conversion of soluble forms of the ions that plants cannot absorb (Werner et al. 2004). The highest value (1.74\%) was observed at the second sampling period. On the other hand, Fe contents in plants remained the same in both first and second sampling periods followed by an increase in the third sampling period (Fig. 2). The highest value of plant Fe (1.98\%) was found to be at the third sampling period.

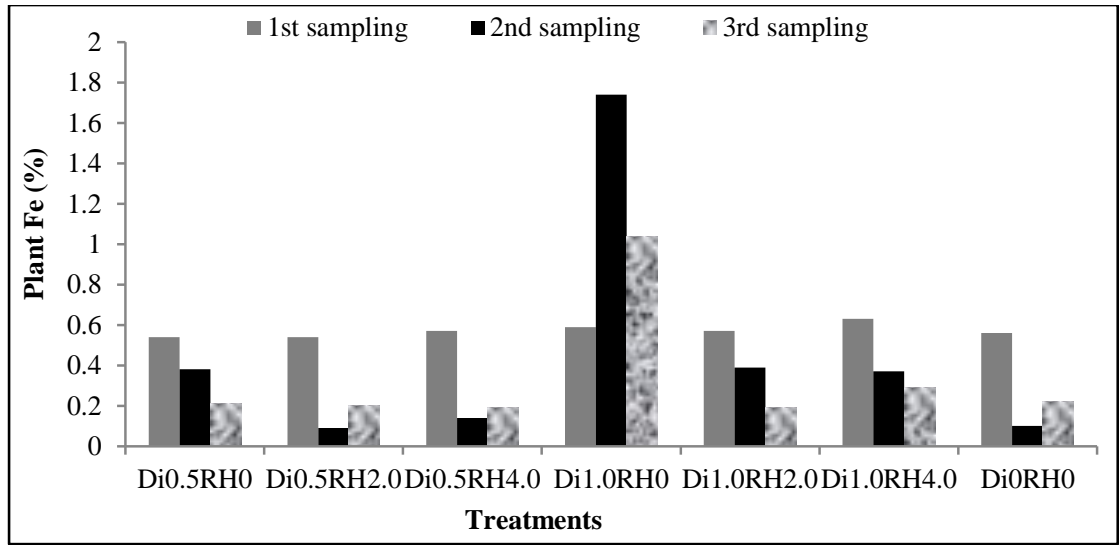

Fig. 2. Plant iron at different treatments during three sampling periods. 


\section{Effect on diazinon content}

Initially, before application of any treatment, the soil contained $0.87 \mathrm{ppm}$ diazinon. It was observed that diazinon content of the soil was increased and then decreased at third sampling period for all treatments including the control (Fig. 3). It was evident that there is a strong relationship between soil $\mathrm{pH}$ and diazinon concentration. Diazinon undergoes hydrolysis reaction when soil $\mathrm{pH}$ is high. The more alkaline the water, the more rapidly the pesticide breaks down. The hydrolysis can be very fast when the $\mathrm{pH}$ of the water is greater than 8 . For every unit increase in $\mathrm{pH}$, the rate of hydrolysis increases about ten times (Lotti and Moretto 2005).

The highest amount $(0.51 \mathrm{ppm})$ of soil diazinon was found at second sampling period. In case of $\mathrm{Di}_{0.5} \mathrm{RH}_{0.0}$ (treatment 1), $\mathrm{Di}_{0.5} \mathrm{RH}_{2.0}$ (treatment 2) and $\mathrm{Di}_{0.5} \mathrm{RH}_{4.0}$ (treatment 3), the highest amount of diazinon was reduced from plant by rice hull during third sampling period. For $\mathrm{Di}_{0.5} \mathrm{RH}_{2.0}$ (treatment 2), where $0.5 \mathrm{ml}$ of diazinon and $2 \mathrm{~kg}$ of rice hull were added to soil and the concentration diazinon compound in the plant was found to be reduced in three sampling periods. It means rice hull as bioremediant yielded 0.267, 0.693 and 0.023 ppm, respectively (Fig. 4). Diazinon content in the plant followed the similar trend like the soil diazinon. Except the control treatment $\left(\mathrm{Di}_{0.5} \mathrm{RH}_{0.0}\right.$-treatment 1), diazinon contents in the plants were increased and then decreased in third sampling period. The highest value $(0.885 \mathrm{ppm})$ was found for the second sampling period.

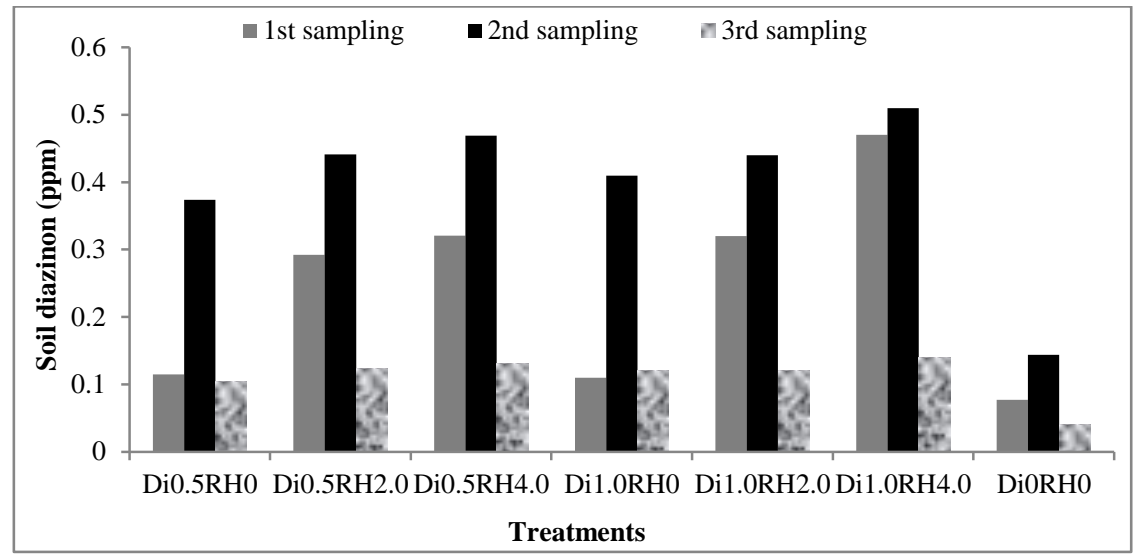

Fig. 3. Soil diazinon at different treatments during three sampling periods.

In case of $\mathrm{Di}_{0.5} \mathrm{RH}_{4.0}$ (treatment 3), where $0.5 \mathrm{ml}$ of diazinon and $4 \mathrm{~g}$ of rice hull were added to soil, the reduced amounts in the plants were found to be $70,22.16$ and $99.48 \%$, respectively during three sampling periods (Table 1). It indicates that it quickly restricted the pesticide absorption when rice hull was added, but the pesticide became persistent with time and less amount of pesticide was reduced. Again during the third sampling period, when the rice hull was totally decomposed it reduced mostly 98\% pesticide.

For $\mathrm{Di}_{1.0} \mathrm{RH}_{0.0}$ (treatment 4), $\mathrm{Di}_{1.0} \mathrm{RH}_{2.0}$ (treatment 5) and $\mathrm{Di}_{1.0} \mathrm{RH}_{4.0}$ (treatment 6), the same observation appeared although the pesticide dose was doubled. In case of $\mathrm{Di}_{1.0} \mathrm{RH}_{2.0}$ (treatment 5), the percent reduction of diazinon compound in plant was 85.8, 79.54 and 96.83\%, respectively during the three sampling periods. For $\mathrm{Di}_{1.0} \mathrm{RH}_{4.0}$ (treatment 6), the percent reduction of diazinon was 80.40, 49.14 and $99.49 \%$, respectively (Table 1). However, in case of $\mathrm{Di}_{0.0} \mathrm{RH}_{0.0}$ (treatment 7), where no pesticide and rice hull was added, a little amount of pesticide was found in both soil and plant samples because of the behavior of the pesticide. 


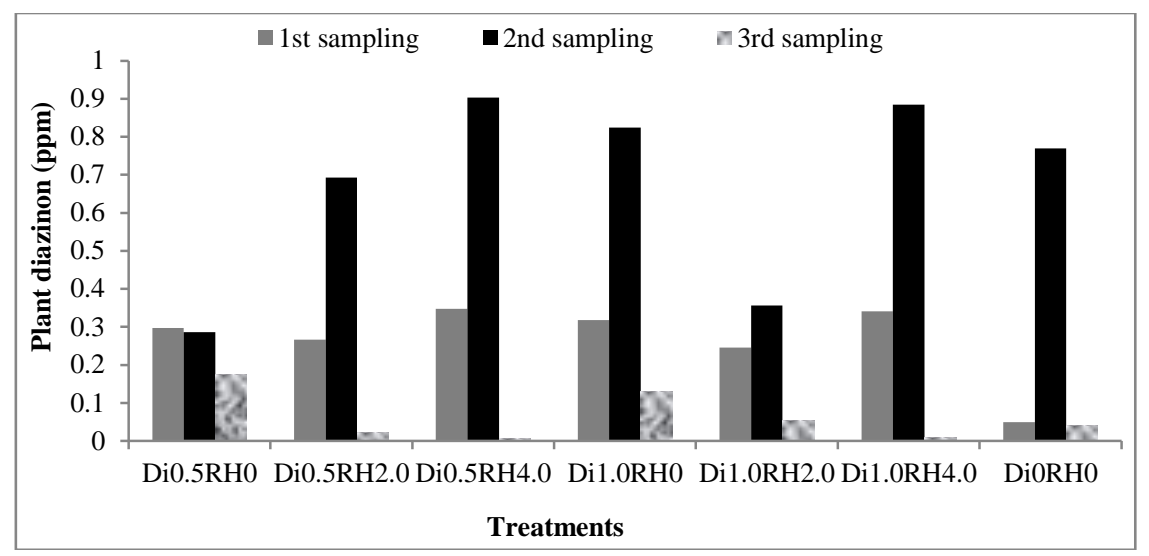

Fig. 4. Plant diazinon at different treatments during three sampling periods.

It is apparent from the present study that rice hull as a bioremediant reduced the uptake of diazinon by plants from soil. When the dose of bioremediant was doubled, less amount of diazinon reduction occur in plant than $2 \mathrm{~g}$ dose of rice hull. Thus, the dose of $2 \mathrm{~g}$ rice hull was the better dose than the dose of $4 \mathrm{~g}$ as bioremediant in reducing diazinon compounds in plants. It was revealed that rice hull as bioremediant was able to restrict the uptake of pesticides by plants and could bring the pesticide into the soil system. The amount of pesticide material in plant as well as food chain could be minimized by using such bioremediant.

Table 1. Reduction of diazinon in percent in the plants at three sampling periods after adding rice hull to soil.

\begin{tabular}{lccc}
\hline Treatment & \multicolumn{3}{c}{ Reduction of diazinon (\%) } \\
\cline { 2 - 4 } & $\mathbf{1}^{\text {st }}$ sampling period & $\mathbf{2}^{\text {nd }}$ sampling period & $\mathbf{3}^{\text {rd }}$ sampling period \\
\hline $\mathrm{Di}_{0.5} \mathrm{RH}_{2.0}$ (treatment 2) & 76.98 & 40.26 & 98.02 \\
$\mathrm{Di}_{0.5} \mathrm{RH}_{4.0}$ (treatment 3) & 70 & 22.16 & 99.48 \\
$\mathrm{Di}_{1.0} \mathrm{RH}_{2.0}$ (treatment 5) & 85.8 & 79.54 & 96.83 \\
$\mathrm{Di}_{1.0} \mathrm{RH}_{4.0}$ (treatment 6) & 80.40 & 49.14 & 99.49 \\
\hline
\end{tabular}

Rice hull helped the soil to release more Fe and made it available for plant uptake. Therefore, the Fe was highest in plant at the last sampling period. Application of diazinon initially affected soil, but it disappeared from soil with time due to degradation, evaporation, transportation, etc. Extractable diazinon was highest at the initial stage, but depleted gradually with consequent increase in bound-up forms in humic substances and soil fractions. At the second sampling period, diazinon content was highest in both soil and plant. As the rice hull served as bioremediant, it restricted the uptake of diazinon by plant and soil. Thus, rice hull showed positive response in case of bioremediation and this finding is important because the harmful effects of pesticide can be minimized and/ or controlled by using rice hull as bioremediant. It will ultimately lead to reduced production cost, environmental pollution and indiscriminate use of pesticides.

\section{REFERENCES}

Ahmed, H. 1982. Personal communication at Bangladesh Agricultural Research Council (BARI), Dhaka.

BARC (Bangladesh Agriculture Research Council). 2012. Fertilizer Recommendation Guide. Soils Publication No. 45. 274 pp. 
Behera, B. and S. G. Singh. 1999. Studies on weed management in monsoon season crop of tomato. Indian J. Weed Sci.31(1-2): 67.

Brian, J. A. 2012. Heavy metals in soils: trace metals and metalloids in soils and their bioavailability. Environ. Poll. 22: 59-67.

Carter, M. R. and E. G. Gregorich. 2007. Soil Sampling and Methods of Analysis. 2nd ed. CRC Press, Taylor and Francis Group, USA, pp. 115-230

Fanrong, Z., A. Shafaqat, Z. Haitao, O. Younan, Q. Boyin, W. Feibo and Z. Guoping. 2011. The influence of $\mathrm{pH}$ and organic matter content in paddy soil on heavy metal availability and their uptake by rice plants. Environ. Poll. 159(1): 84-91.

Habibullah, A. K. M. and S. M. I. Huq. 1992. Impact of intensive agriculture, hydrochemicals and population on the quality of environment in Bangladesh. Paper presented at the seminar on 'Environmental Soil Science', Alberta, Canada.

Huq, S. M. I. and M. D. Alam. 2005. A handbook on analysis of soil, plant and water. BangladeshAustralia Centre for Environmental Research (BACER-DU), University of Dhaka, Dhaka, Bangladesh, pp. 63-153.

Jackson, M. L. 1958. Soil Chemical Analysis. Prentice-Hall Inc, New Jersey. 498 pp.

Lotti, M. and A. Moretto. 2005. Organophosphate-induced delayed polyneuropathy. Toxicol. Rev. 24(1): $37-49$.

Russell, C. and C. B. Schultz. 2009. Effects of grass-specific herbicides on butterflies: an experimental investigation to advance conservation efforts. J. Insect Conserv. 14(1): 53-63.

Shegunoa, P., J. Klanoa and I. Holoubek. 2007. Residues of organochlorinated pesticides in soil from the Czech Republic. Environ. Poll. 146(1): 257-261.

Toan, V., V. Thao, J. Walder, H. R. Schmutz and C. Ha. 2007. Contamination by selected organochlorine pesticides (OCPs) in surface soils in Hanoi, Vietnam. Bull. Environ. Cont. Toxi. 78(3): 195-200.

Werner, H., O. Goddert, F. Agnes, M. Hartmut and W. Christina. 2004. Relationship between pH values and nutrient availability in forest soils - the consequences for the use of ecograms in forest ecology. Flora. 199: 134-142. 